\title{
From briefing, through scenario, to debriefing: the maritime instructor's work during simulator-based training
}

\author{
Charlott Sellberg ${ }^{1}$ (D)
}

Received: 20 December 2016 / Accepted: 3 November 2017 / Published online: 10 November 2017

(C) The Author(s) 2017. This article is an open access publication

\begin{abstract}
Simulator-based training in maritime education is an illustrative and paradigmatic example of how the introduction of high-end technologies creates new challenges for instructors: using simulators in educational settings for teaching skills that must be transferred to a professional work practice. This study draws on ethnographic fieldwork and video recordings of learning activities in a maritime navigation course to investigate the instructional challenges and opportunities for connecting general learning lessons to practical situations in different phases of simulator-based training. In particular, taking on a situated action approach, the research questions concern how the participants are orienting towards general instructions from the prospective briefing phase in the subsequent scenario and debriefing phases of training, considering how the social and material resources in the simulator environment organize the learning activities. The results show that connecting the general to the specifics of navigational situations is a continuous instructional achievement that is maintained throughout all stages of training, from briefing, through scenario, to debriefing. Hence, the results are stressing the importance for both inscenario instructions and post-simulation debriefing in order to facilitate learning towards a profession. Moreover, the results emphasize how technologies in the simulator environment offer opportunities for instructors to continuously monitor, correct and assess the students' activities towards the learning outcomes.
\end{abstract}

Charlott Sellberg

charlott.sellberg@gu.se

1 Department of Education, Communication and Learning, University of Gothenburg, Box: 300, 40530 Gothenburg, Sweden
Keywords Simulator-based training - Maritime education and training $\cdot$ Socio-material recources $\cdot$ Temporal organization $\cdot$ Situated action

\section{Introduction}

This article provides an analysis of the different phases in simulator-based training to investigate how the maritime instructor is connecting general learning lessons to specific situations during learning activities that take place in a simulator environment. Simulators are known to provide opportunities to train for complex and advanced technological work tasks in high-risk professions such as the nuclear industry (e.g. Theureau 2000), aviation (e.g. Roth et al. 2015) and health care (e.g. Manser and Wehner 2002) in a risk-free manner. In the maritime domain, simulators are used for training towards several aspects of the maritime industry, from offshore operation training on vessels and oilrigs to onshore training of crane operations and vessel traffic services (VTS), offering possibilities for professional training in educational settings (Crichton 2016). In the literature, simulation-based training is often discussed as a matter of technical fidelity or realism of the simulator. Since the nature of situations encountered in high-risk professions is complex and dynamic, it is considered important for the simulator to resemble the work setting the students are training for in order for skills to transfer to professional practice (see e.g. Dahlstrom et al. 2009). In a study on simulators in health care, Rystedt and Sjöblom (2012) have shown that realism and relevance of simulation-based training also are an instructional concern, since clinical work practices have to be addressed through professional guiding and feedback in a systematic way. Their results have been supported also by studies on the use of simulators in maritime education 
(e.g. Hontvedt and Arnseth 2013; Sellberg 2016). Hence, perceiving the simulation a realistic and work relevant learning activity is both an instructional concern and a matter of the technical design of the simulator.

In simulator-based training, learning activities are structured to make the most out of the practical exercise, and instructors are known to put effort into scaffolding and reflection to promote learning (Hontvedt and Arnseth 2013). Training in simulators regularly involves three phases that offer different material and temporal conditions for instruction. First the instructor introduces the assignment to the whole student group, a so-called briefing. The introduction is commonly focused on practical information regarding the upcoming scenario and the learning objectives (Wickers 2010). After briefing, a scenario plays out in the simulator. In the current study, the students work collaboratively in bridge operation simulators, which combine the physical space of a ship's bridge with digital projections of the marine environment. In navigation courses, a scenario can be, for example, to navigate at open sea in restricted visibility, to navigate in narrow waters and to navigate in heavily trafficked waters. These kinds of exercises are used to train proficiency of handling the instruments on the ship's bridge, as well as bridge teamwork and appliance of the rules that regulate traffic at sea. Lastly, a debriefing is carried out. In the literature, debriefing is described as a post-experience analysis and group reflection of the scenario. Debriefing has been described to "transform experience into learning" (Hontvedt and Arnseth 2013, p. 92) and a way to integrate theoretical knowledge with practical experience (Fanning and Gaba 2007). For these reasons, the debriefing phase is often described as especially important for learning: helping the participants to understand, analyse and synthesize their experiences, thoughts and feelings during the scenario (e.g. Fanning and Gaba 2007). As a consequence, several pedagogical models for facilitating reflection in debriefing have been developed, mainly in health care (e.g. Fanning and Gaba 2007; Rudolph et al. 2007; Neill and Wotton 2011).

The study is designed as a workplace study, an approach to research that aims towards gaining in-depth understanding of how people use technologies in their day-to-day activities (Suchman 2000). Workplace studies have been described as "taking the social and situated aspects of work seriously", providing holistic views of work practices (Sellberg and Lindblom 2014, p. 467). The workplace study approach implies that this study draws on ethnographic fieldwork and video-recorded data to do an interaction analysis of the participants' activities in the simulator setting. The analytical framework used draws mainly on situated action (Suchman 2007) to investigate how the instructors' connecting general learning lessons to specific situations are put on display in the different phases of simulator-based training. It is through analysis of how the members themselves coordinate their actions to accommodate to their asymmetrical understanding towards the educational setting's protocols and purposes the inner function of a practice can be found according to Suchman (2007). Hence, professional practice is being produced and reproduced through the specific practices as carried out by members of the profession. In particular, taking on a situated action approach, the research questions concern how the participants are orienting towards general instructions from the prospective briefing phase in the subsequent scenario and debriefing phases of training, considering how the social and material resources in the simulator environment organize the learning activities. As highlighted by Button et al. (2015), Suchman showed that instructions are always accountable in action, occasioned by and contingent on realizing them.

The article is structured as follows: first, in Sect. 2, the theoretical framework of the study is presented as well as some background into a situated view on simulator-based training. In the following section, Sect. 3, the workplace study research design is presented, which is followed by analyses of the different stages of training (Sect. 4). The result of the analysis is concluded and discussed in the final section of the article (Sect. 5).

\section{Theoretical background}

This study takes on a situated action approach (SA) (Suchman 2007). In Suchman's analysis on humans interacting with a photocopier, she suggested a new approach to research on human-computer interaction: using methods for analysing face-to-face conversations as the basis for human-machine communication. The main idea was not to ascribe the machine with intent, but rather assume that the machine, like humans, is behaving in accordance with the resources provided by "its" situation and that the user is behaving in accordance with the resources of hers (Suchman 2007). Plans and situated actions were an attempt to criticize the cognitive planning model that was dominant at the time, viewing the plan as an underlying mechanism for action, and Suchman built her critique partly by using navigation as an illustrative case. In a cognitive perspective, a plan is viewed as a sequence of actions that are designed to meet a desired goal state. From such a perspective, planning is tightly related to the student mariners' prior knowledge on the environment and the situations that will probably arise, as well as unforeseen events that require re-planning or an alternative plan to fall back on. In contrast, Suchman's approach situated action in its material and social circumstances to find how intelligent behaviours are local productions rather than products of rational planning, as even in those cases action is indeed planned for. From this perspective, plans have in common with instructions that they both are partial, but can 
function as general prescriptions for action and their use is contingent on the particular occasion in which they are applied:

Stated in advance, plans are inherently vague, insofar as they must accommodate the unforeseeable contingencies of particular situations. Reconstructed in retrospect, plans systematically filter out precisely the particularity of detail that characterizes situated actions, in favour of those aspects that can be seen to accord to the plan (Suchman 2007, p. 26).

Hence, instead of building a theory of actions from plans, Suchman's interest was to find how people use their plans in the course of situated actions. The plan is one of the resources that guide the moment-by-moment sequential organization of actions, but "they do not lay out a sequence of work that then is blindly interpreted" (Dourish and Button 1998, p. 406).

As can be seen, SA is not a theory of cognition and learning per se. The inspiration for a situated approach of actions came from sociological writings on ethnomethodology (Garfinkel 1967), and conversation analysis (Sacks 1992), approaches dedicated to studying what is publicly available in interaction, and how mutual intelligibility and objectivity are constituted in social facts. Hence, with the theoretical underpinnings of the approach, the aim is to find evidence of the settings protocols and purposes in turns of talk between participants: to find the inner function of the practice in the unfolding of the events under analysis (Suchman 2007). In this way, SA is suitable for analysing the instructional practices in educational settings where knowledge is coconstructed between instructors, students and the material environment.

\subsection{A situated perspective on simulator-based training}

Studies that take situated perspectives on simulator-based training emphasize that the development of professional knowledge is an interactional matter as well as an instructional concern since the relevance or irrelevance of different simulated activities has to be systematically addressed through professional guiding and feedback by an instructor (Rystedt and Sjöblom 2012). As highlighted in a study on simulators in dental education, the simulator by itself does offer little in terms of learning (Hindmarsh et al. 2014). The simulator technology does not teach the student how to perform a manual skill or a professional bodily technique, or any explanations on why the task should be accomplished one way and not another. Results from simulators in maritime training support seem to this view. For example, Hontvedt and Arnseth (2013) highlight that while the ship simulator shows great potential as an educational tool, what is simulated during training far exceeds the simulator. As their analysis show, the student's meaning making activities were highly depending on the instructor's work of designing and facilitating simulations as a relevant activity context, i.e. a context where participants are solving certain work-related tasks (Linell and Thunqvist 2003).

When taking a SA approach to study the different phases of simulator-based training, briefing, scenario and debriefing, the prospective instructions in the briefing phase of simulator-based training are seen as mere reasoning about actions rather than a generative mechanism of action in a later stage. It is first in the course of actions, when problems are encountered, that instructions for action become useful according to Suchman (2007). The interpretations that are made when using the instruction then are questions of being able to transform talk into practical action during the scenario phase: to know how to go on. Instructions in the course of actions are contingent on a social and material environment that resembles aspects of a real work setting. The sensitivity to the material and social context in instruction is known to address matters of skill acquisition and "draws pedagogical strength from exploitation of the unique details of particular situations" (Suchman 2007, p. 45). Furthermore, instructions in the course of actions are often designed as a series of corrections (Lindwall et al. 2015). The reason for this is that actions are "essentially transparent to us actors" (Suchman 2007, p. 60). When breakdowns in knowing how to go on occur, the action becomes less elusive and more open for reasoning than when things are proceeding smoothly. In this way, errors and mistakes open up for inspection and correction in the midst of action. In retrospect, when the outcome of the assignment is known, it is possible to assess the appropriateness of performed actions. At this time, the prospective plan is revisited to filter out the particularities that accord or diverge from the initial plan (Suchman, 2007). In the literature on simulator-based training, the debriefing phase is often described as especially important for learning in helping the participants to make sense of their experience from the scenario (e.g. Fanning and Gaba 2007). In simulation-based training, it is a common practice to use different technologies that reconstructs the scenario to enable post-simulation feedback and reflection. In health care, the use of video-assisted debriefs has been studied (see e.g. Johansson et al., 2017). Findings show how video in debriefing is used for reactualizing prior events and thus is enabling assessment of the participants conduct as well as opening up for discussions on what good work practices are (Johansson et al. 2017). However, Johansson et al. (2017) findings highlight that the instructor plays a decisive part in guiding the students to see the recorded events in ways that are relevant for the professions they are training for. Hence, Johansson et al. (2017) show that such reflections are collaborative achievements rather than individual ones. 
In simulator-based maritime training, the use of simplified visualizations has been discussed as providing significant opportunities for learning (Hontvedt and Arnseth 2013). A pedagogical benefit of such technologies is that they provide a record of actions during the scenario that makes these actions accountable. In this way, the actions taken are publicly observable and discussable, opening up for collaborative discussions and reflections amongst group members. But as Hontvedt and Arnseth (2013) point out, simplified visualizations do not provide any records of what the participants talk about during simulation, and propose the use of video-assisted debriefs also in maritime training. Although the usefulness of different debriefing technologies has been acknowledged, results from Neill and Wotton (2011) literature review point towards the need for more research that explores the use of different debriefing methodologies. In sum, the use of simulators and simulator technologies that promote reflection in education shows clear potential for training skills and developing professional knowledge. However, the instructor's work of organizing and facilitating the learning activities before, in and after action is crucial for meeting such learning objectives.

\section{The empirical case and research design}

The simulators in the current study are located at a maritime simulator centre at a technical university that offers education in several areas of the maritime domain: navigation, engineering, cargo handling, resource management and marine environment. The maritime department has approximately 630 students and 100 employees in three bachelor programmes: master mariner, marine engineering and shipping and logistics. The department also provides several master programmes and a research school. The simulators at the centre are used both for educational purposes and for research and include cargo operation simulators, machine room simulators, simulators used for radio communication and several types of navigation simulators ranging from desktop simulators to high-fidelity full mission bridge simulators. The navigation course that is in focus in the current study is part of a four-year master mariner's programme and takes place during the students' second year. The course consists of both lectures and practical learning activities, designed to meet the learning objectives of the course and the international conventions that regulate maritime training. It consists of both lectures and practical learning activities: lectures that are mainly focused towards the use of technologies used in navigation, i.e. Radar and ARPA equipment, the anti-collision regulations (COLREG) that serve as "Rules of the Road" at sea, communication between vessels and bridge team communication and operations. Practical exercises consist of six simulation-based training sessions, including a driving test at the end in order to certify students on their proficiency in handling instruments and applying COLREG. At the simulator centre under study, there are five different bridge operation simulators that combine the physical space of a ship's bridge with digital projections of the naval environment. During exercises, all students are simultaneously taking part in the same scenario, communicating and coordinating with each other in the same traffic situation. Moreover, there are also other representations of vessels preprogrammed in the simulation, which at times are manipulated by the instructor to create different situations. The scenario in the current study is to pass Great Belt, a strait between Danish islands Zealand and Funen. There are several navigational challenges in such a scenario; the waters are narrow, traffic is heavy, and there is the Great Belt Bridge to pass. Each scenario is designed with the intention to lead students into a challenging situation where mistakes are easily made. The pedagogical idea behind this, as explained by the instructors, is that when errors or mistakes are made it opens up for retrospective discussions that the whole group can learn from in the debriefing phase.

Drawing on SA, a workplace study approach was considered suitable for the study. The approach aims at naturalistic studies of technical work and learning practices and ethnographic fieldwork and analysis of video data are considered essential parts of the method to render such practices visible (Heath et al. 2011; Suchman 2000). During a period of 2.5 years, observations of simulator-based training and informal interviews with maritime instructors have been conducted. Ethnographic fieldwork was crucial in this study for developing an understanding of the educational content in the navigation courses and the instructional activities that are embedded this specific cultural context. However, in order to collect data that allow for close and detailed interaction analyses, approximately $75 \mathrm{~h}$ from five different training sessions were video-recorded. When using multiple cameras to capture interactions that were distributed in time and space in the simulator environment, close to $400 \mathrm{~h}$ on video was generated. Spending time in the field identified different instructional practices at work during training sessions, which guided the selection of video material chosen for further analysis. In all, approximately 50 episodes were identified from two of the training sessions, which were transcribed and analysed with focus on interactions between instructor, students and their material environment. For this study, episodes from one of the scenarios, Passing Great Belt, were used for tracing instructions throughout the different phases training. The chosen excerpts can be considered representative of the instructional practices that take place during simulations. They represent the routine work practices that take place during simulations, and the use of a variety of different technologies in the simulator environment when technologies working as 


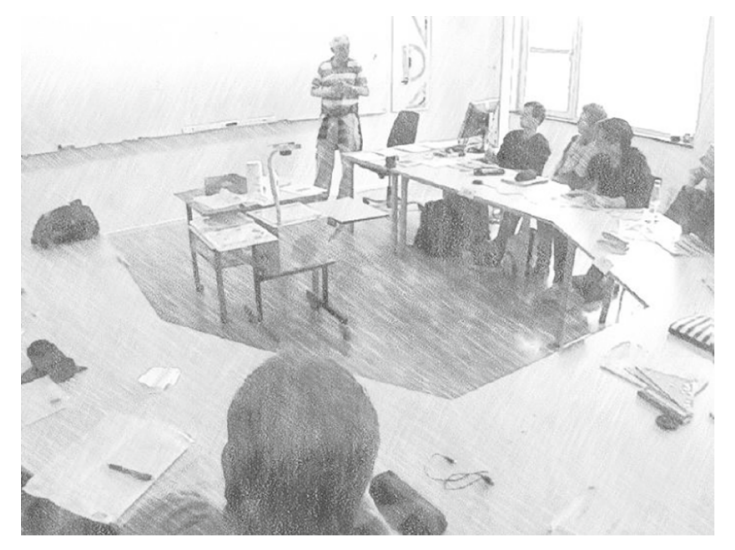

\section{Passing Great Belt}

Show your intentions!

Turn with autopilot $\mathrm{r} 0,5 \mathrm{M}$ or handsteering

ARPA vs. TRAILs vs. visual conduct?

Safe speed $16 \mathrm{kt}$ or $12 \mathrm{kt}$

Radar Range?

Crossing ferries follow COLREG!!!

Using PIs on good radar target

Fig. 1 The classroom environment and the content of one of the PPT used in briefing

expected (however, technical problems arise at times, but this is beyond the scope of this study). With the theoretical underpinnings of taking an SA approach, the analytical focus is on participants and how they analyse each other: whether that analysis is taking place in face-to-face interactions, or indirect, actions as seen through the technologies used. Moreover, the analyses concern how the participants' understanding of each other is displayed from one turn to the next in the transcribed interactions (cf. Suchman 2007).

\section{Analysis}

In this section, the learning activities in the simulator environment are analysed. The students work collaboratively in teams of two in exercises during scenarios, taking turns of practicing the different work roles of officer-of-the-watch and lookout, performing the work order of the bridge team on board a technologically equipped ship. On the bridge, it is the officer-of-the-watch that has the responsibility of taking navigational decisions. During scenarios, the student who is taking this role will be expected to take overall control of the exercise by planning the course, taking positions and steering the ship. The lookout is collaborating with the officer, mainly by keeping a close lookout onto the marine environment as projected on the screens in the simulator and by monitoring the radar technologies. Moreover, the students are training the communicative practice of closedloop communication, meaning that when the sender gives a message, the receiver repeats it back. The closed-loop format is used both on the bridge and between vessels to avoid communicative misunderstandings. During scenarios, the instructor monitors the exercise from the instructor's room in the near proximity of the bridges. The instructor's room contains several computer screens showing different aspects of the students' work, and the instructor is working actively with the technology to monitor what is happening on each bridge and how that affects the scenario as a whole. Before and after simulator training sessions, briefings and debriefings are held in the briefing room. The briefing room is a classroom next to the simulators. Here common classroom technologies for presentations such as PowerPoint (PPT) and overhead machines are commonly used alongside analogue tools such as writing and drawing on a whiteboard or referring to paper-based information. In debriefing, a playback of the scenario is used which lays the ground for collective discussions about the scenario. In the following section, the briefing phase is analysed with focus of how the general learning lessons are organized and introduced with attention on primarily two of the instructions: instructions regarding COLREG and instructions regarding how to gather the appropriate information amongst different information sources on the bridge. In the subsequent sections, the analyses concern how the participants orient towards these instructions in the scenario and debriefing phases of training, maintaining a focus on the social and material resources in the simulator environment in the different phases.

\subsection{Briefing: open and prospective instructions for the whole group}

The briefing is carried out in a classroom next to the simulators and serves as an introduction to the assignment. In the classroom, the desks are placed in a horseshoe shape (Fig. 1). The spatial layout sets the frame for instruction, where each bridge team has their own marked places, which places the students of each team next to each other even before the scenario plays out. The whiteboard is placed at the front of the class, a design that places the instructor in a traditional position in front of the class. Information about the upcoming scenario is presented to the whole group of ten students by means of a PPT presentation. The PPT format offers a sequential structure, which is unpacked slide by slide and used to integrate visual media with verbal instruction, 
illustrating what is being said. In this way, the instructor is establishing joint attention on different aspects of the day's assignment one point at a time: some more elaborated on and others just briefly mentioned (cf. Lymer et al. 2009).

In this prospective phase of training, the instructor relates or discusses the more general learning objectives in relation to the particularities of the upcoming scenario. When the scenario task is to pass the Great Belt, the instructor uses the case to talk about the appropriate instrument to use or the appropriate anti-collision rules (COLREG) to apply in such narrow and trafficked waters. Here it is seen how some of the instructions in the PPT are formulated as directives, e.g. "Show your intentions!" or "Crossing ferries follow COLREG!!!" or suggestions as what a safe speed is in the upcoming scenario. These directives are connected to COLREG, a set of rules that provide some general guidelines for application (Belcher 2002). For example, it is stated in the guidelines that all actions should be "positive, obvious and made in good time", but no specific distances, time frames or exact actions are formulated in the regulations. Instead, actions should be based on "good seamanship", which is highly situation dependent (Taylor 1998). As Taylor (1998) points out, the regulations are socially defined, which indicates that the meaning of, for example, "safe distance" is a mutual agreement between vessels, taking into account the circumstances of the situation. It is also interesting to notice the exclamation marks on instructions connected to COLREG, highlighting the importance to follow these instructions in particular. These rules always apply at sea, and the students will be held accountable for following them both in the scenario phase and in debriefing, in the upcoming driving test, and in their future work practice. The verbal instructions regarding these points are generally brief; the instructor mainly highlights that " $\ldots$ as always COLREG and good seamanship applies".

Other instructions on the PPT are formulated as questions, e.g. "Radar Range?" or "ARPA ${ }^{1}$ vs TRAILS ${ }^{2}$ vs visual conduct?" The questions posed address hands on matters on how to use the instruments on the bridge to gather appropriate information for making navigational decisions. Which observational method is most suitable is a matter of the circumstances of the situation, depending on aspects such as visibility and proximity, but visual lookout should always be favoured when possible (cf. Hontvedt 2015). Although these points are formulated as questions, the instructor answers them himself, using these questions as a starting point for

\footnotetext{
1 Automatic Radar Plotting Aid (ARPA) is a system used to calculate other object's course, speed and distance.

2 The trail function is a tail-like, historical representation of each vessel's movements on the Radar. It is mainly used to assess targets' speed and course.
}

instruction. These instructions are often more elaborated than the straightforward directives, but the main message from the instructor to the students in the briefing is that using the appropriate instrument or setting is depending on situation at hand, highlighting their responsibility to always be attentive towards the situation.

The instructions can be seen as quite open and straightforward. The openness of the instructions serves two important functions. First, the group will be divided into five different bridge teams in the scenario. Even if each team is given the same task, every team will be given a different point of departure, as well as a different destination, and thus has slightly different prerequisites during the scenario. Hence, the openness of the instruction is necessary in order to address each team's different prerequisites. Second, according to Suchman (2007) instructions often take the form of general templates for actions since it is impossible to specify all the different possibilities that might arise in the actual situation. The formulations of instructions are necessarily open because they are so inherently contingent on the specific circumstances of the situation in which they apply. In briefing, the students are evidently unaware of the contingencies that will arise in the upcoming scenario, for example, which and how much traffic they will meet. Hence, these instructions answer questions that the students do not know the relevance of yet. What the students do know on the other hand is that they should use radar functions and that they are responsible for following COLREG, and they ask few questions in regard to this during briefing. Students' knowing that they should follow such general instructions, and how they are able to actually apply these instructions in practice then becomes a matter of a much more complex sort. It is a classical problem of the instruction follower, of turning open and partial descriptions into concrete and practical activities towards a desired outcome (cf. Suchman 2007).

\subsection{Scenarios: Immediate and detailed corrections on the bridge}

In the following examples from the scenario phase, the participants are orienting towards the general instructions in the briefing phase: the straightforward direction to follow COLREG (Episode 1) and the question of which observational method to favour in different situations "ARPA vs TRAIL vs visual conduct" (Episode 2). What both episodes have in common is that they are occasioned by the instructor's monitoring of the students' actions from the instructor's room (Fig. 2). Here, the instructor can monitor the settings of instruments on the different bridges, audio-visual recordings of the students' teamwork and data that make it possible to see the students' lookout on the environment. An overall view of the scenario as a whole is also possible: on one screen, the actions of each vessel are visualized from a 


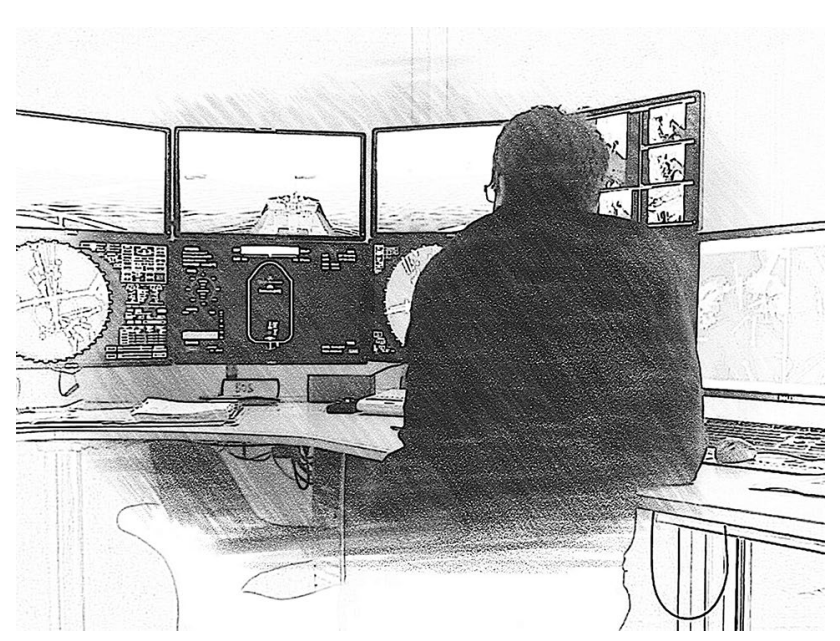

Fig. 2 The different technologies available in the instructor's room, providing both overview and detail on the students' actions

bird's-eye perspective. Representations such as the trails that grow behind each vessel are enabling the instructor to see the actions taken, providing assessable traces of what has been done. Furthermore, representations such as the vectors pointing in the directions that the vessel is taking are giving the instructor an insight into the students' moment-tomoment navigational decisions, opening up for interventions when the students are displaying troubles in knowing how to go on towards the desired outcome. In Suchman (2007), it is highlighted that mistakes render otherwise transparent action visible, opening up for closer inspection and correction. In both episodes, instructions take a corrective form as the instructor is providing the students with accounts of what the instruction means in the particularities of specific situations, instructions that are supporting the students in carrying out their task towards the desired outcome of crossing Great Belt in accordance with the rules. Even if the technology only offers a partial view "through a very small keyhole" (Suchman 2007, p. 11), the technological infrastructure in the instructor's room opens up for a shared view between instructor and the student team work on the bridge. It is these radar and monitoring technologies that make the students' actions during scenarios visible for, and thus accountable, to the instructor.

The first episode is an example of a correction mediated by radio from the instructor's room. These kinds of radiomediated role-playing instructions are regularly seen in the simulator environment, and their overall function, according to the instructors, is to provide instructions with minimal interference. Furthermore, these instructions aim to train the students to communicate in a professional manner, as well as learning to coordinate and collaborate with other vessels through the communicative practices of the profession. In this example, the instructor monitors the different bridges and notices that the students' bridge team, controlling the simulated tank ship Cilla, is getting too close to another ship in the Dover strait: a working ship named Deep Surveyor. The situation encountered is a matter of applying the general instruction to follow COLREG, but to know exactly which sets of rules that apply to this particular situation. In order to follow the instruction correctly, the students have to identify that Deep Surveyor is a working vessel by integrating information from the lights and shapes that the vessel is carrying (seen trough a visual lookout) and the $\mathrm{AIS}^{3}$ (on the bridge panel). After identifying the type of vessel, they have to realize their responsibility towards the vessel in accordance with rulebook and make a navigational decision to take proper action. As the students are getting too close to the other vessel for the distance to be considered safe, the violation of COLREG is opening up for closer inspection and a correction. In this episode, the instructor uses the radio in the instructor's room to call the students' bridge, taking on the role of captain of the Deep Surveyor. The instructor speaks English and has changed his voice into a more nasal tone, asking the students to go to a different radio channel for communication. Over a minute goes by before one of the students in her role as commanding officer on the bridge controlling Cilla responds:

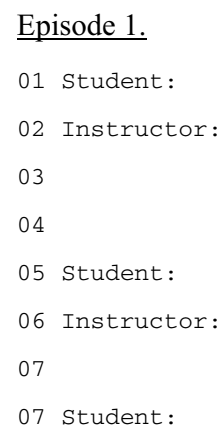

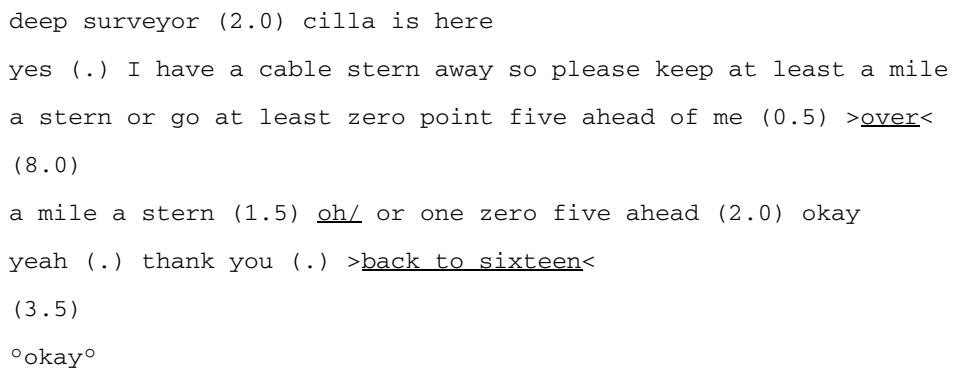


The student's response in line 01 is both an account of receiving the call and showing that she is taking the responsibility as commanding officer on the bridge. The time that goes by before the student answers, the extended pause between the first part of the sentence and the latter, as well as forgetting to deliver the word "over" to mark the end of the sentence displays that the student still is learning to communicate in line with the professional practice. The instructor's response in the next turn is packed with meaning and serves several purposes (line 02-03). First, the talk provides information about the kind of ship they are approaching (a surveying vessel carrying cable), what distance to keep ("at least a mile" or "at least zero point five"), and which actions that would be appropriate to take in the present situation (go a astern or go ahead). In this way, the instructor's call has a corrective function, highlighting that the bridge team on Cilla is getting too close to the other vessel for it to be considered a safe distance in this particular situation, but also cues about why the distance they are keeping is considered too close. In this instance, the role-playing instructor is supporting them with accounts of what "follow COLREG!!!" means when applying several sets of rules that are relevant to the particularities of the situation, giving them an instruction of what "too close" is when meeting a certain kind of vessel. The student's response in line 03 is in line with the practice of closed-loop communication, repeating back the instructed distances to keep, but marking the end of her talk with an "okay" (line 07) rather than the correct "over", again revealing that she is not yet fully in the discourse of maritime communication. The instructor is not addressing these communicative mistakes and is ending the call with an instruction to go back to the main channel for communication again.

Although providing more detail than the vague instruction from briefing, the accounts here are also partial since "it reveals certain features and hide others" (Dourish and Button 1998, p. 423). For example, the accounts reported do not explicitly point out the specific rules that apply in this situation or that the students are in fact breaking the rules. Rather, the organization of the instruction as a role-play, using the maritime professions way of communicating, maintains the activity as a task of manoeuvring a ship (cf. Rystedt and Sjöblom 2012). At the same time, the organization of the instruction is hiding the fact that it is a correction, and it becomes vague if the students' that are receiving it recognizes it as a correction: during the turns of talk, the student was merely reaping back the instruction. This can be seen as making an effort to maintain the role-play as communication between vessels rather than an exhibited understanding of the underlying purpose of the instructors call to the bridge. The student's response in line 03 is interesting here. In this instance of talk, the student's uttering "oh" (line 05) suggests that she is now realizing that their vessel is in some kind of problematic situation, but the minimal utterance is not displaying much of how the student understands the instructor's accounts, or the lesson that is being taught here. The instructor treats the student's responses as insufficient and makes a second call to the students on the bridge after a few minutes. This time to ask the students whether they had checked their AIS, and when they answer that they did not, he provides them with a straightforward directive to do so, making sure that the students understand the intervention as a correction. In this way, the instructor clarifies the lesson to be learned here, the need of being aware of which type of vessels one meet in traffic, again connecting the situation to COLREG that apply differently depending on if the ship type of the meeting vessel and the responsibilities towards it.

The accounts reported in the episode does not arise out of the students' request for information; rather, they are interventions that happen because the students' conduct goes against a certain instruction, "follow COLREG", from the briefing phase, and the instructor identifying their conduct as breaking the rules. This is the case also in the second episode, and the instructor has seen how the students on bridge Ada are entering a close-quarter situation with other vessels in the Great Belt area and are joining the students in the simulator in order to facilitate them through the situation: 


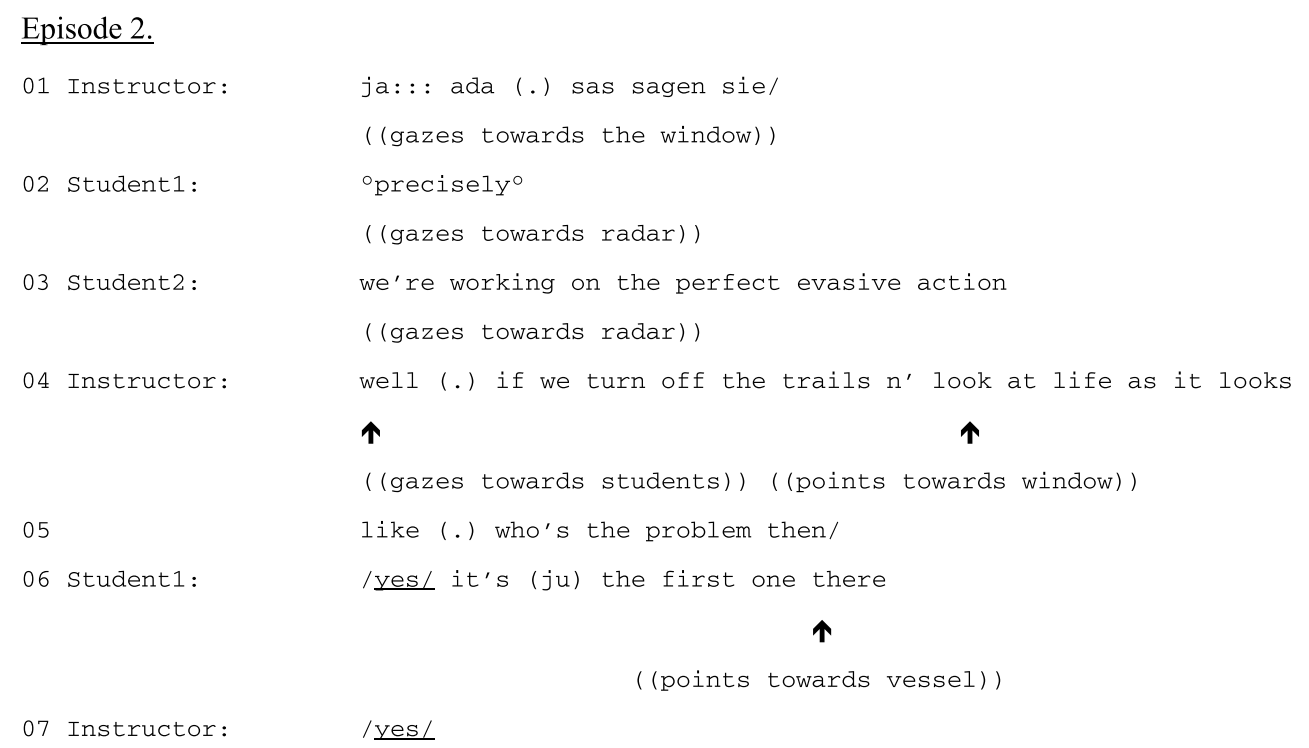

The instructor opens the conversation with a question in German, which translates into "what do you say" (line 01). These kinds of opening utterances in another language than Swedish are commonly seen on the bridge and in general serve dual purposes of both marking the instructor roleplaying as the highest-rank officer of a vessel and servers as a requests for a response of how the students understand the current situation. The students in this situation respond in Swedish, which then becomes the language for the following turns of talk. The utterance made by Student1 here is quiet and seems to be addressing something else than the instructor's question (line 02). Student1 who is standing in front of the starboard radar is taking the role as officerof-the-watch, and he is gazing quite focused into the radar display. Student 2 that answers the question is standing in front of the portside radar, taking the role of lookout. Thus,

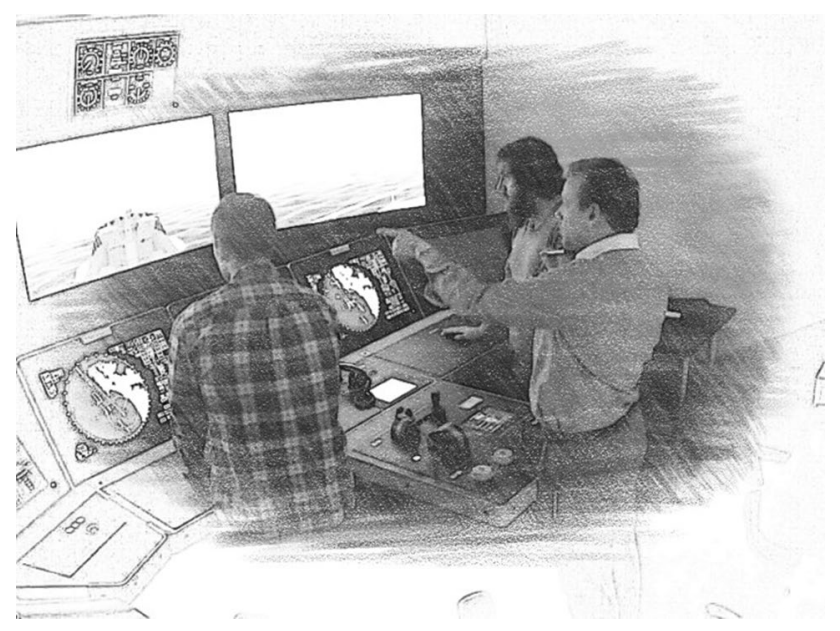

Fig. 3 Lookout through the window in of the bridge operation simulators this is an episode where the students are not collaborating to participate in the role-play of bridge teamwork, going against the maritime hierarchy the role-play is highlighting (cf. Hontvedt and Arnseth 2013). The answer that is provided by Student 2 can explain this: the students are working on an evasive action, trying to get out of a problematic situation where actions have to be taken to avoid a close-quarter situation, or even collision, with another simulated vessel. Hence, their focus at this time is not on working order on the bridge; rather, they are trying to solve an acute problem, displaying an understanding that they are aware of the problematic situation, and are taking responsibility to follow the instructions when actively trying to solve it.

For the instructor, being there with the students on the bridge enables a detailed assessment of the situation, in this case by instructor orienting towards the students' gazes for determining their methods for assessing the situation. Similar to flying an airliner (Nevile 2011) or driving a car (Haddington and Keisanen 2009), looking is a critical feature of navigating a modern ship. In addition to looking out the window to see what is going on outside, work on the bridge is dependent on monitoring a number of instruments for navigation such as radar and electronic charts. Thus, looking at the right place at the right time is critical for the professional practice of a navigator. In the briefing phase, instructions addressed the matter of deciding between ARPA, TRAILS and a visual lookout. In this instance, both students are looking down on their respective radar images, trying to understand the situation and solve the problem using radar and the TRAIL function as the primary source of information. In this situation where the students are navigating in good visibility, the appropriate professional conduct is to favour the visible lookout on the environment instead on relying on technology. The radar display that the students are attending to provides an overview of the unfolding situation, but 
distances between vessels have to be interpreted and calculated in relation to scale. In contrast, using a visual lookout on nearby traffic provides direct information about proximity (Fig. 3).

As seen in, for example, Nevile (2011), gaze shifts make visibly available how the participants understand what is going on. The instructor's orientation towards the student's gaze opens up for making a correction on this behaviour: a verbal instruction is made in lines 04-05 alongside a hand gesture to direct the student's attention towards the window (Fig. 3). When following the instruction and lifting his gaze, Student1 delivers an answer: "Yes! It's (ju) the first one there". Here, it is not just what is said that is important, but how it is said. While "Yes" is delivered with a higher pitch, the use of the Swedish word "ju" indicates that this is something the student understands by the new outlook on the situation perceived when looking out of the window. The indexical utterance "there" is matched with a pointing hand gesture, showing "there" to be another vessel seen through the window, exhibiting his new understanding of the situation (cf. Hindmarsh et al. 2011). The instructor treats this as a correct answer, delivering a "Yes!" that is mimicking the student's utterance. Hence, the correction addresses the matter of managing gaze and attention, of looking at the right place at the right time to integrate the appropriate type of information in this particular situation. In this way, the instructive talk and the environmental coupled gestures are showing students how to choose the appropriate information when multiple information sources are available. If looking back to the prospective instructions in briefing in which students were instructed what information and instruments could be useful to gather information, these instructions draw on the specific details of the scenario to point out when the recommended information is useful. Hence, corrections on the bridge afford instructions on complex matters of rule appliance and skill acquisition that are difficult to address anywhere else, at any other point in time, since they address the specific contingencies that occur in the midst of action. It is first in the course of action that general instructions from the briefing phase such as "follow COLREG" or instructions to use different technologies for navigation are made relevant and can be applied in a way that develop the students' professional skills and technical proficiency. It is these immediate and detailed instructions that "keep the roof up" to borrow the exact words of Suchman (2007, p. 80) and are teaching the students how to do the practice as a professional.

\subsection{Debriefing: revisiting prospective instructions to make assessments}

During the debriefing phase, the instructor starts with providing a general review of how the students as a group performed during the scenario by revisiting the instructions from the briefing phase. For this purpose, the instructor uses a PPT presentation with different points for reflection on the actions taken. As in the case with the PPT in the briefing phase, the presentation is produced in advance by the instructor to highlight aspects of the scenario related to the learning objectives of the course. In this way, the initial plan is revisited in retrospect. According to Suchman (2007), revisiting the plan filters out precisely the particularity of situated actions and favours those aspects that can be seen to accord to the plan. Although this part of debriefing is similar to the briefing phase, there are some essential differences. In the prospective phase, students listen to instructions in order to know "how to go on" (cf. Shotter, 1996). After the experience is made, the instructor's talk is about

\section{Reflections on exercise}

Did you show your intentions?

Did you check/follow PIs?

ARPA vs. TRAILs vs. visual conduct?

Did you take positions?

Did you follow COLREG?

Did you identify ship signals?

Did other think you gave enough space?

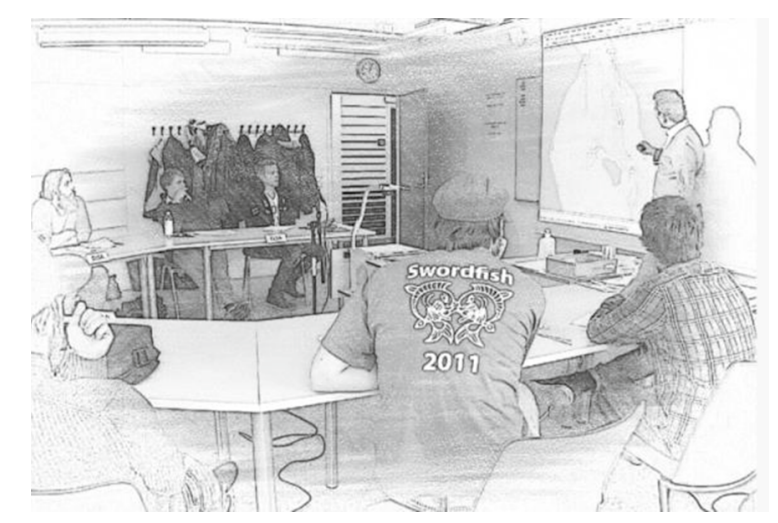

Fig. 4 The instructor uses a PPT and a playback of the scenario in the debriefing phase 
their prior actions. It is also interesting to reflect on how the exclamation marks of the directive to "follow COLREG!!!" in this phase are replaced with a question mark. But rather than using these questions as a baseline for student discussions, the instructor mostly answers them himself, providing the students with general assessments of their performance during the scenario. The reason for this practice can be that the ability to discriminate between what is relevant information and what is irrelevant, or "noise" as Suchman (2007, p. 113) puts it, is part of expert knowledge. At this point in debriefing, no single student or student team is singled out, and the assessment is generally directed to the group as a whole. For example, to answer the question: Did you follow if the students followed COLREG? The instructor makes a comment that they mostly did or that they did "so and so" depending on the performance of the group as a whole.

After the general review of the scenario, the exercise is played back on a projection screen (Fig. 4). Through its design, the playback becomes a visualization that provides a simplified representation of the situation from a bird'seye view. As the students' manoeuvring actions serve as input to the system, they leave an "assessable trace" (Suchman 2007, p. 46) and trail starts to grow behind each vessel. During the debriefing, movements of vessels and their trails render the actions taken by the students during the scenario visible and thus accountable. When starting the playback, the instructor points out each of the students' vessels on the screen, along with short walk-throughs of the teams' actions. The playback serves as a basis also for more elaborate discussions on mistakes and errors that occurred during scenarios, i.e. situations when students failed to follow instructions from the briefing phase. In the following example, we are revisiting the close-quarter situation with a surveying vessel that was taken as examples on corrections mediated by radio to see how the mistake of the bridge team on Cilla becomes an example to learn from for the whole class:

\section{Excerpt 3.}

01 Instructor:

07 Students :

08 Instructor:

13 Student1:

14 Student2:

15 Student1:

16 Instructor: and then we have (.) Cilla coming down to Deep Surveyor

((pointer on Cilla)) ((pointer on Deep Surveyor))

and then they have some communication

$\mathrm{e}: \mathrm{h}(1.0)$ and what's interesting here is that when Cilla is

close and they have communicated (0.5) e:th (.) one can think

that Deep Surveyor should have said something earlier but it

wouldn't have been this interesting then

( (laugh))

e:th (.) for the sake of the discussion (.) it was so eventless

for them anyways (.) e::h (.) that they have cable behind (.)

and you could think that Cilla maybe could figure out that Deep

Survevor here (.) e:th (.) are doing some kind of work and

then display the signal=

((hand gesture toward student group))

=inhibited (0.5) or=

=restricted

/yeah/ /restricted/

/restricted manoeuvrability/ e: :h (.) right of way (.) then you

should keep a reasonable distance ahead or astern (.) and in

this case they want to have at least one mile astern because

they are laying out cable (.) or at least half a mile ahead

(.) and things like this you should take with you (.) to always

keep these distances (.) if not for their sake it's for your

own (.) not to get caught in something then (.) huh/ 
In this episode, the instructor starts with pointing out the vessels involved in the situation that becomes the topic of discussion (line 01). The first point is on the students' vessel Cilla, followed by a sweeping move with the pointer towards Deep Surveyor, showing how Cilla came down to the surveying vessel in the strait. In this way, the instructor's gestures are highlighting and establishing shared attention on the critical aspects of this particular situation. It is followed in line 02 with a comment on that the vessels "had some communication". This communication cannot be seen in the playback's simplified representation of the marine environment and the spatial positions between vessels. Instead, such assessments draw on the instructor's observations on the students' work on the bridge from the instructor's room and the written notes he makes during the scenario. What the playback offers is a partial view of the outcome of the student's behaviour, a small "keyhole" into the navigational work done during the scenario (cf. Suchman 2007).

In the following turns (turns 03-09), we can see how the instructor talks about bridge team Cilla's mistake as something that was designed by the instructor to make the scenario more of a learning lesson. Such accounts make it possible to use errors from individual bridge teams as examples for the whole class without blaming specific students for mistakes and hence maintaining a positive atmosphere in the classroom. The students' laughing (turn 07) can be seen as co-participating in maintaining a positive atmosphere, helping easing the potential tension of critique in front of the group. The instructor continues this account with a comment that was in sake of the discussion (turn 08). The comment is underlining that bridge team Cilla was doing well in the exercise, the instructor himself taking responsibility for the situation. However, in the continuation of the talk the instructor highlights that "one can think that Cilla could figure out" (line 10) that Deep Surveyor is a working vessel, both by emphasizing the later part of the surveying vessels name and that the vessel can be identified by looking at the signal they are carrying (line 12). In this way, the responsibility of a bridge team is again highlighted.

Towards the midst of the talk, the instructor leans forward, making a gesture towards the class, inviting them to finish his sentence and thereby displaying their understanding of the signal such a vessel would carry (line 12). The students that respond to this question are the officerof-the-watch (Student1) and lookout (Student2) on bridge team Cilla (turns 13-15). Here we can see how they are still collaborating as a team after they have left the bridge, at this time to find the exact formulation from the rulebook. Although the accounts reported in Episode 1 and the debriefing discussion of the event never explicitly point towards a certain rule in COLREG, the students show that they are aware of the exact formulation of that specific rule by quoting Rule 18 that to the letter. The instructor confirms this as a correct answer by repeating back the response and continues the instruction with an account of what it means to have restricted manoeuvrability; the other vessel has the right of way in this situation, and thus, the students on Cilla are responsible for giving way. Furthermore, we can see how the instructor takes the particular details of this situation and connects them with something generally important when following COLREG: the need to gather information about nearby vessels by attending to the information available, but also to at all time maintain safe distances to other vessels, also for your own sake (turns 16-22).

\section{Discussion and conclusion}

This study examines how the participants in simulator-based training are orienting towards the general instructions from the briefing phase in the subsequent scenario and debriefing phases of training, considering how the material resources in the simulator environment organize the learning activities. In the briefing phase, instructions are by necessity rather open and straightforward since the specific contingencies of the scenario are yet unknown. For the students, this is a classical problem of the instruction follower: turning open and partial descriptions into concrete and practical activities towards a desired outcome (cf. Suchman 2007). It is first during scenarios that general instructions from briefing can be delivered in a way that take the contingencies of specific situations into account. It is these immediate and detailed instructions that "keep the roof up" (cf. Suchman 2007, p. 80 ), providing instructions on professional matters of rule appliance and skill acquisition that are difficult to address anywhere else, at any other point in time, since they are sensitive towards the specific details of the context in the midst of action. The analysis shows how the instructor monitors the students' work on the bridges from the instructor's room. The technological infrastructure in the instructor's room opens up for a shared but partial view between the instructor and the students on the different bridges that enables assessment of the students ongoing conduct during the scenarios and occasions corrections when the students are not following the instructions given in briefing. Corrections can be performed both from the instructor's room, mediated by radio, in a manner that maintains the activity and in the simulator. Instructions on the bridge operation simulators on the other hand draw on a rich context of material and social resources. For the instructor, being there, in the midst of action, enables taking the students' perspective of the situation at hand. Furthermore, the instructor being there enables attending to specific details of the students conduct; such as how they are managing their gaze and attention when integrating information from different sources on the bridge. In 
debriefing, a PPT that is produced by the instructor is used to revisit the instructions from the briefing, reconnecting the scenario to the learning objectives and affording assessments in general terms. Reconnecting back to the prospective instructions enables the instructor to make a general assessment of how the student teams were doing in the scenario, providing accounts on how the group in general did. The use of simulator technologies, in this case a playback of the scenario, makes it possible to reconstruct the students' prior actions and enables instruction and assessment of specific details in the students' conduct. When the scenario is played back, each individual bridge teams actions during the scenario phase become publicly observable, and thus accountable, opening up for feedback on a variety of issues involved in the practice of navigation. These results are in line with the literature on debriefing, describing this phase as a way to integrate abstracted knowledge with practical experience (e.g. Fanning and Gaba 2007). Furthermore, while the debriefing models generally highlight the importance of reflection, analysis and discussion (e.g. Fanning and Gaba 2007; Rudolph et al. 2007; Wickers 2010 ), these empirical findings show that the instructors' questions during debriefing mainly are directed towards assessment and feedback, with guidance by an instructor rather than facilitating student discussion and self-reflection in line with the results from Eikeland Husebø et al. (2013) and Johansson et al. (2017). Hence, it is important to stress that the debriefing models found in, for example, Fanning and Gaba (2007) or Rudolph et al. (2007) are merely models. That is, idealized and simplified pictures on how debriefing should be carried out, rather than accounts of actual debriefing practices. Taking a situated approach challenges a well-established picture of debriefing as moulding participants' experiences through self-reflection and discussion and that other aspects of debriefing are found to be more essential, such as assessment and feedback (cf: Eikeland Husebø et al. 2013; Johansson et al. 2017).

In the literature on simulations, the matter of bridging general lessons learned with the experience made during simulations is often attributed to the debriefing phase (e.g. Fanning and Gaba 2007; Wickers 2010). The results from the current study makes explicit that connecting general learning lessons to specific situations is a collaborative achievement, maintained throughout all stages of training through the participants' orientation towards the instructions both in and after action. Hence, the results stress the importance also for in-scenario instructions in order to facilitate development of professional knowledge and skills. In sum, the use of simulators and simulator technologies in education show clear potential for training skills and developing professional knowledge. However, the instructor's work of organizing and facilitating the learning activities before, in and after action is crucial for meeting such learning objectives. The conclusions also emphasize the importance of systematic professional guidance and feedback in simulator-based training, supporting results from research on simulators in training, in health care (Rystedt and Sjöblom 2012), dental education (Hindmarsh et al. 2014) as well as maritime training (Hontvedt and Arnseth 2013). These studies highlight that the simulator itself offer little in terms of learning, emphasizing that what is simulated as far more important that the simulator. What this study contributes with is a view of what the simulator does offer for learning: more than being a relevant context for professional training, the simulator environment is also providing the means for the instructor to monitor, correct and assess the student towards desired learning outcomes (cf. Sellberg, 2016).

In addition, the results from this study highlight the importance of the pedagogical tools in the simulator environment, i.e. the technologies in the instructor's room and the playback used in debriefing. These technologies do not teach the students how to perform manual skills, or provide any accounts of why the task should be accomplished one way or another (cf. Hindmarsh et al. 2014). What these technologies provide are an opportunity to observe the students' activities and in this way enable the instructor's work of correcting and assessing the students' conduct towards the desired outcome, facilitating learning the profession. While the use of PPT in debriefing is targeting learning objectives that is not easily discussed from what is publicly accessible in the playback, it does not provide any accountable records of the team work on the bridge. Instead, other representational formats, such as video-based debriefs, could be useful in order to address such learning objectives by providing type of stable and accountable records that affords detailed assessments and open up for discussion and reflection (Hontvedt and Anseth 2013; Johansson et al. 2017). The opportunities for instruction that such technologies offer have been studied in debriefings, but there is still a need for more studies that are exploring and contrasting the use of different debriefing technologies (Neill and Wotton 2011). It also seems to be a lack of studies that analyse the use of monitoring technologies that enable instruction during scenarios. Such technologies are briefly mentioned in Hontvedt and Arnseth (2013) and in Hontvedt (2015) but deserve attention on its own right, since the instructor's work is so reliant on the monitoring the student's work. The practice of organizing instructions as role-play is also interesting. In this study, it is apparent that role-playing while correcting the students maintains the activity as a task of manoeuvring a ship, but at the same time the correcting might not be heard as $a$ correction. In line with Rystedt and Sjöblom (2012), these results show that learning how to simulate deserves more attention in research on simulator-based training. 
Acknowledgements The study is part of the project "Training skills and assessing performance in simulator-based learning environments", which is a collaboration between the Department of Mechanics and Maritime Sciences at Chalmers University of Technology and the Department of Education, Communication and Learning at University of Gothenburg. The project is financed by four parties: the University of Gothenburg Learning and Media Technology Studio (LETStudio), the Linnaeus Centre for Research on Learning, Interaction and Mediated Communication in Contemporary Society (LinCS), Department of Mechanics and Maritime Sciences at Chalmers University of Technology and Department of Education, Communication and Learning at University of Gothenburg. I would also like to thank the following senior researchers for their critical and constructive comments on the text in different stages of the writing process: Hans Rystedt, Oskar Lindwall and Mona Lundin. I am also most grateful towards the instructors and students at the simulator centre for their participation in the project.

Open Access This article is distributed under the terms of the Creative Commons Attribution 4.0 International License (http://creativecommons.org/licenses/by/4.0/), which permits unrestricted use, distribution, and reproduction in any medium, provided you give appropriate credit to the original author(s) and the source, provide a link to the Creative Commons license, and indicate if changes were made.

\section{References}

Belcher P (2002) A sociological interpretation of the COLREGS. J Navig. 55(2):213-224

Button G, Crabtree A, Rouncefield M, Tolmie P (2015) Deconstructing ethnography: towards a social methodology for ubiquitous computing and interactive systems design. Springer, New York

Crichton MT (2016) From cockpit to operating theatre to drilling rig floor: five principles for improving safety using simulator-based exercises to enhance team cognition. Cogn Technol Work. https:// doi.org/10.1007/s10111-016-0396-9

Dahlstrom N, Dekker S, Van Winsen R, Nyce J (2009) Fidelity and validity of simulator training. Theor Issues Ergon. https://doi. org/10.1080/14639220802368864

Dourish P, Button G (1998) On" technomethodology”: foundational relationships between ethnomethodology and system design. Human Comput 13(4):395-432

Eikeland Husebø S, Dieckmann P, Rystedt H, Søreide E, Friberg F (2013) The relationship between facilitators' questions and the level of reflection in postsimulation debriefing. Simul Healthc. https://doi.org/10.1097/SIH.0b013e31827cbb5c

Fanning RM, Gaba DM (2007) The role of debriefing in simulation-based learning. Simul Healthc. https://doi.org/10.1097/ SIH.0b013e3180315539

Garfinkel H (1967) Studies in ethnomethodology. Prentice Hall Inc, Englewood Cliffs

Haddington P, Keisanen T (2009) Location, mobility and the body as resources in selecting a route. J Pragmat. https://doi.org/10.1016/j. pragma.2008.09.018

Heath C, Hindmarsh J, Luff P (2011) Video in qualitative research: Analysing social interaction in everyday life. SAGE Publications Ltd, London

Hindmarsh J, Reynolds P, Dunne S (2011) Exhibiting understanding: the body in apprenticeship. J Pragmat. https://doi.org/10.1016/j. pragma.2009.09.008

Hindmarsh J, Hyland L, Banerjee A (2014) Work to make simulation work: 'Realism', instructional correction and the body in training. Discourse Stud. https://doi.org/10.1177/1461445613514670
Hontvedt M (2015) Professional vision in simulated environmentsExamining professional maritime pilots' performance of work tasks in a full-mission ship simulator. Learn Cult Soc Interact. https://doi.org/10.1016/j.1csi.2015.07.003

Hontvedt M, Arnseth HC (2013) On the bridge to learn: analysing the social organization of nautical instruction in a ship simulator. Int J Comput Support Collab Learn 8(1):89-112

Johansson E, Lindwall O, Rystedt H (2017) Experiences, appearances, and interprofessional training: the instructional use of video in post-simulation debriefings. Comput Support Learn. https://doi. org/10.1007/s11412-017-9252-z

Lindwall O, Lymer G, Greiffenhagen C (2015) The sequential analysis of instruction. In: Markee N (ed) The Handbook of classroom discourse and interaction, pp 142-157. Wiley, Malden, MA

Linell P, Thunqvist DP (2003) Moving in and out of framings: activity contexts in talks with young unemployed people within a training project. J Pragmat. https://doi.org/10.1016/ S0378-2166(02)00143-1

Lymer G, Ivarsson J, Lindwall O (2009) Contrasting the use of tools for presentation and critique: some cases from architectural education. Comput Support Learn. https://doi.org/10.1007/ s11412-009-9073-9

Manser T, Wehner T (2002) Analysing action sequences: variations in action density in the administration of anaesthesia. Cogn Technol Work. https://doi.org/10.1007/s101110200006

Neill MA, Wotton K (2011) High-fidelity simulation debriefing in nursing education: a literature review. Clin Simul Nurs. https://doi. org/10.1016/j.ecns.2011.02.001

Nevile M (2011) Looking for action: talk and gaze home position in the airline cockpit. Aust Rev Appl Linguist 33(1):3.1

Roth WM, Mavin TJ, Munro I (2015) How a cockpit forgets speeds (and speed-related events): toward a kinetic description of joint cognitive systems. Cogn Technol Work. https://doi.org/10.1007/ s10111-014-0292-0

Rudolph JW, Simon R, Rivard P, Dufresne RL, Raemer DB (2007) Debriefing with good judgment: combining rigorous feedback with genuine inquiry. Anesthesiol Clin. https://doi.org/10.1016/j. anclin.2007.03.007

Rystedt H, Sjöblom B (2012) Realism, authenticity, and learning in healthcare simulations: rules of relevance and irrelevance as interactive achievements. Instr Sci. https://doi.org/10.1007/ s11251-012-9213-x

Sacks H (1992) Lectures on Conversation vol: I-II. In: Jefferson G (ed) Oxford. Blackwell, UK

Sellberg C (2016) Representing and enacting movement: the body as an instructional resource in a simulator-based environment. Educ Inf Technol. https://doi.org/10.1007/s10639-016-9546-1

Sellberg C, Lindblom J (2014) Comparing methods for workplace studies: a theoretical and empirical analysis. Cogn Technol Work. https://doi.org/10.1007/s10111-014-0273-3

Shotter J (1996) 'Now I can go on:' Wittgenstein and our embodied embeddedness in the 'Hurly-Burly' of life. Hum Stud. 19(4):385-407

Suchman L (2000) Making a case: 'knowledge' and 'routine' work in document production. In: Luff P, Hindmarsh J, Heath C (eds) Workplace studies: recovering work practice and informing system design. Cambridge University Press, NY, pp 29-45

Suchman L (2007) Human-machine reconfigurations: plans and situated actions. Cambridge University Press, New York

Taylor DH (1998) Rules and regulations in maritime collision avoidance: New directions for bridge team training. J Navig. 51(1):67-72

Theureau J (2000) Nuclear reactor control room simulators: human factors research and development. Cogn Technol Work. https:// doi.org/10.1007/s101110050031

Wickers MP (2010) Establishing the climate for a successful debriefing. Clin Simul Nurs. https://doi.org/10.1016/j.ecns.2009.06.003 